\title{
Saudação ao Professor Miguel Reale, por Ocasião da Concessão do Título Professor Honoris Causa da Universidade Federal do Rio Grande do Sul
}

Ao encarregar-me de proferit, em nome de minha Universidade, a saudação ao Doutor Honoris Causa, Professor Doutor, Miguel Reale, o Professor Doutor Sérgio Porto, Diretor da Faculdade de Direito, não me conferiu tão somente a honra - a maior que poderia ter - de honrar aquele que nos honra, integrando-șe agora, de direito, aos nossos quadros universitários. Conferiu-me, por igual, a imensa responsabilidade de tentar sintetizar, em breves minutos, uma vida, uma obra, um pensamento que atinge, da poesia à hermenêutica, da política ao direito, da filosofia à administração universitária, da metafísica aos fatos do cotidiano brasileiro, as maiores alturas, as mais profundas acuidades.

Não falarei do Miguel Reale poeta, embora dele recolha metáforas iluminantes; nem do Miguel Reale da Teoria Política; nem do memorialista; nem mesmo do filósofo. Falarei, em primeiro lugar, do Professor - pois é assim que é aqui recebido. E falarei também do jurista - mais até - do civilista, pois deste falando, falarei, por certo, de todos os 'Miguel Reale", porque sua obra jurídica maior - o Código Civil de 2002, o Código Reale - de certa forma estampa, acolhe e revela todos os muitos Miguel Reale.

Os muitos Miguel Reale, sim, porque nosso novo colega - doutor dessa Universidade, e de mais 14 universidades onde recebeu o mesmo título Honoris Causa - não é, felizmente, um especialista. É um humanista na mais larga acepção da palavra, pois tudo o que é humano é do seu interesse. Um interesse que não é de catalogação ou erudição, mas de compreensão. Ësse é o traço que procurarei primeiramente ressaltar, pois não faria sentido expor para todos nós que tão bem conbecemos sua obra e sua trajetória intelectual - alunos que fomos e somos - arrolar, burocraticamente, suas realizações ou transcrever o seu pensamento.

Em um ensaio intitulado "Reale no Recife", o Professor Gláucio Veiga sintetiza admiravelmente, o primeito traço que hoje quero sublinhar, o do professor (e que posso comprovar, pessoalmente, dando o testemunho da nossa estreita convivência 
nos úitimos 8 anos, dos riquíssimos - para mim - fins de semana passados na fazenda Campo Verde, em conversas que nunca são banais): Diz Veiga:

"Reale ensinou-nos que os assuntos ou são temas, ou problemas, ou agonias, Quando enfrentamos os assuntos como temas, surge a servidão à citação, à erudição, enfím a inevitável buroctatização da inteligência, que se resume a confetir concordância e discordância, enfim a inventariar o que já se disse. Mas, se tomarmos os assuntos como problemas e, mais tragicamente, como agonias, impõe-se a criatividade, o construir intelectualmente".

Esse é o mestiere do verdadeiro professor: tratar os assuntos como problemas, construindo, intelectualmente, caminhos, perspectivas - e perspectivas são sempre responsabilidades hermenêuticas, que são dadas pela nossa própria profissão, responsabilidades que temos - e desenvolvemos, ou não. Que podemos matar com a burocratização de um conhecimento que se perverte na cópia, na imitação, na subserviência ao paradigma da moda, no transplante e na colagem.

O Professor Reale não matou a sua responsabilidade de professor - pelo contrário, da sua vida resulta uma iluminante construção intelectual, e não apenas na filosofia, terreno onde cultivou o mais denso pensamento brasileiro, aquele expresso em Verdade e Conjectura; não somente na Teoria do Direito, na qual assentou as bases de uma axiologia da experiência humana. Também construiu no que o Direito tem de mais árido, a sua legislação e aqui o professor encontrou-se com o filósofo e o jurista prático, o advogado brilhante e ativo que aos 92 anos é.

Ao planejar o novo Código Civil - ao estruturá-lo, direcioná-lo às suas diretrizes fundamentais, a socialidade, a eticidade e a operabilidade - ao conferir à legislação algumas de suas soluções mais criativas, Reale expressou o seu culturalismo, que é visão integral da realidade, na qual os diferentes fenômenos culturais que a integram são entendidos desde as suas relações dialéticas, relações de co-implicação e complementatidade. E procurou - por meio de sua esrrutura e de seu método conciliar o relativismo (que advém da consideração histórico-cultural dos valores) com o universalismo e a estabilidade dos valores necessários para manter, preservar e dignificar a vida bumana ${ }^{1}$, traduzindo-os em princípios e regras.

Uma das mais perspicazes estudiosas da obra realeana, a filósofa espanhola Angeles Mateos $\mathrm{Garcia}^{2}$ observa que o problema tratado mais diretamente em suas últimas obras é o de saber como é possível conciliar a relatividade axiológica própria

\footnotetext{
${ }^{1}$ Assim MATEOS, Angeles, La Teoria de los Valores em Miguel Reale. Uma síntesis superadora entre el culturalismo y el universalismo axiológico. In Miguel Reale - Estudos em Homenagen aos seus Noventa Anos. (org). ZILLES, Urbano. Porto Alegre, EdiPUCRGS, 2000, p p. 271

${ }^{2}$ MATEOS, Angeles, La Teoria de los Valores em Miguel Reale. Uma síntesis superadora entre el culturalismo y el universalismo axiológico. In Miguel Reale- Estudos em Homenagem aos seus Noventa Anos. (org). ZlLLES, Urbano. Porto Alegre, EdiPUCRGS, 2000, p p. 271-272.
} 
de uma concepção histórico-cultutal dos valores, com a exigência de uma série de princípios e regras fixos e estáveis que possam garantir a convivência na sociedade pluralista e transversal da nossa época. Reale enfrenta esse problema por meio de duas direções: o personalismo axiológico, buscando nos direitos fundamentais da pessoa fonte e fundamento para todos os demais valores, de um lado; e, de outro, a sua teoria das invariantes axiológicas pela qual põe de relevo que existem valores que, apesar das incessantes mudanças sociais, permanecem inalterados no tempo.

Para explicar a relação entre o dinamismo e a invariação, Reale recotre, analogicamente, às invariantes biológicas de Monod. As invariantes axiológicas resultam de eleições estimativas que, uma vez objetivadas no processo cultural, perduram no tempo.

O valor da pessoa humana é, para a Reale, a principal invariante axiológica. Por isso é que, quando o jurista, o legislador encontrou-se com o filósofo e com o professor, na elaboração do Anteprojeto do Código Civil, o assunto - tutela civil da pessoa humana, de sua personalidade e de seu patrimônio - não foi tratado como "tema", senão como uma agonia.

É que, para Reale, a tutela da pessoa humana numa perspectiva de concreção - e não meramente fotmalista, como uma abstração - é o problema fundamental, cuja fundamentalidade e prohlematicidade mais se acentuam tendo presente a atual "transvetsalidade" social que nos obriga a fazer o trânsiro do sujeito de direito (como elemento da relação jurídica) à pessoa humana (como valor-fonte do ordenamento).

Essa forte metáfora - a pessoa humana como "valor fonte' - não tem, para Reale, meramente o sentido de uma proclamação: tem um sentido específico, compreensível nos quadros da filosofia realeana. Explicitando-a, assinala Brás Teixeira:

para o mestre paulista, a pessoa não se configura apenas como algo individualizado entre as coisas devido à sua racionalidade, nem se define por ser uma substância ou uma realidade subsistente por si própria e, nessa medida, incomunicável, mas sim por se apresentar como um centro constitutivo de valores, como fulcro de um mundo, o da vida ética, contraposto ao da natureza. A pessoa é, para Miguel Reale, um valor radical e o único incondicionado, mas que, ao mesmo tempo, condiciona, necessariamente, todo o processo espiritual de actualização das virtualidades criadoras do espírito ${ }^{3}$.

Com efeito, em Pluralismo e Liberdade, Miguel Reale proporá "repensar o tema da pessoa em sua concreção social e histórica", para o que essencial é situar,

${ }^{3}$ BRÁS TEIXEIRA, António. A Antropologia Filosófica de Miguel Reale. In

Miguel Reale- Estudos em Homenagem aos seus Noventa Anos, (org). ZILLES, Urbano. Porto Alegre, EdiPUCRGS, 2000, p. 136.

4 REALE, Miguel. Pluralismo e Liberdade. Rio de Janeiro, Expressão e Cultura, $2^{a}$ edição, 1998, p. 81. 
sempre e necessariamente, o problema da pessoa em função da sociedade e da história, revelando-se insuficientes quer uma consideração puramente estática ou ôntico formal da pessoa(...) quer sua apreciação puramente deontológica, à maneira Kanț

Dessa correlação pessoa/sociedade/história nasce a fundamental abertura aos outros, a intersubjetividade, que émuito mais, eédiversa, do que a mera relação entresubjetividades. Dirá:

Pessoa e convivência histórico-social são termos que se exigem reciprocamente, visto como - e este ponto é essencial - pôt-se como pessoa é pôr-se como história, como alteridade, como comunidade ${ }^{6}$.

Isto porque, diz ainda,

O valor da pessoa não está (...) fora da experiência ético-jurídica, mas sim em seu centro, como fulcro irradiante de múltiplas e renovadas projeçóes históricas, por ela condicionadas, de sorte que ousaria aditar o imperativo ético de Kant dizendo: "Sê uma pessoa e respeita os demais, tudo fazendo para propiciar-lbes as condições necessárias ao seuespontâneo eplenodesenvolvimento".

O valor da pessoa humana é fonte de todos os demais valores porque "condiciona a experiência estimativa do homem", de maneira que, "em torno do fulcro central vão se ordenando [na História] constelações axiológicas distintas". E - Direito é instância privilegiada de apreensão, ordenação e concreção social desses valores, dessas "constelaçöes axiológicas" que têm na pessoa humana a sua fonte.

Como eu referi em outra ocasião", na teoria realeana os valores integram o Direito e o próprio conhecimento do Direito, dirigem o olhar do sujeito que o valora e escolhe as suas soluções. Daí que as normas jurídicas constituam o momento integrante e sintético do processo dialético do Direito, que é sempre fato enquanto valorado, ou seja, enquanto norma e situação normada" "'. Chega mesmo a afirmat não ser adequado, a rigor, sequer falar em "norma e situação normada" porque "a norma é, ao mesmo tempo, o condicionante e o condicionado, o valor e o fato em uma síntese dinâmica" "t.

Daí a importância, também no Direito Privado, da hermenêutica concretizadora - tal qual boje postulada no direito constirucional - pois a concreção é

\footnotetext{
${ }^{5}$ REALE, Miguel. Pluralismo e l.jberdade. Rio de Janeiro, Expressão e Cultura, $2^{2}$ edição, 1998, pp. 80-81.

"REALE, Miguel. Pluxalismo e Ljberdade. Rio de faneiro, Expressão e Cultura, $2^{2}$ edição, 1998, p.87.

${ }^{7}$ REALE, Miguel. Pluralismo e Liberdade. Rio de Janeiro, Expressão e Cultura, $2^{2}$ edição, 1998, p. 92, grifos originais.

${ }^{8}$ REALE, Miguel. Pluralismo e Libexdade. Rio de Janeiro, Expressão e Cultura, $2^{2}$ edição, 1998, p.93.

'MARTINS-COSTA, Direito e Cultura; entre as veredas da existência e da história, in Diretrizes Teóricas do Código Civil

10 REALE, Migurel, "De Dignatate Jurisprudentiae", in "Horizontes do Direito e da História", cit., p. 275

${ }^{13}$ REALE, Miguel, "De Dignatate Jurisprudentiae", in "Horizontes do Direito e da História", cit., p. 275Idem, ibidem.
} 
a apreensão compósita da realidade (sempre processus histórico-cultural): é apreensão compósita porque conjuga, normativamente, os elementos fáticos e as diretrizes valorativas, tendo em vista, porém, não o plano da abstração teórica, mas o da realidade prática que o Direito visa ordenar, tendo presente não qualquer cerreza monológica - como queria o cientificismo oitocentista - mas a lógica conjectural ${ }^{12}$, do razoável e do plausível, cujo "confronto e limite" é, sempre, a experiência concreta.

Tudo isso está refletido no novo Código Civil, pensado, por Reale, como uma estrutura agregadora de modelos complexos, rompendo-se a cisão entre "norma" e "interpretação". Antes que a teoria constitucional européia viesse a ensinat - com Muller, Alexy, Haberle - que a norma é o "resultado da interpretação", Reale já pensara o Código como um resultado da "estrutura hermenêutica", a ser completado pelos modelos doutrinários, aqueles que dizem "o que os demais modelos significam".

Como se vê, essas concepções são absolutamente contrastantes com aquela sobre a qual assentou-se o Direito Civil moderno, no qual forjada uma noção abstrata de sujeito de direito centrada na figura do indivíduo considerando, entretanto, como uma abstração social: o indivíduo-sempre-igual, resultante do princípio da igualdade (formal), ao qual correspondia, em termos hermenêuticos, o método da subsunção lógico-sistemática; o indivíduo/sujeito, ao qual não correspondia, necessariamente, a pessoa/cidadã.

Ora, o culturalismo jurídico de Miguel Reale, com sua atenção voltada à noção de experiência jurídica concreta e à lógica conjectural; com sua decisiva rejeição ao formalismo abstracionista - que Reale julga uma "perversão" -, com o olhar voltado à processualidade do processo normativo e à contextualidade que cerca as ações humanas, mostra-se um filtro teórico particularmente indicado para auxiliar o legislador e o intérprete na necessária concreção que viabiliza o encontro das "pessoas" sob a capa dos "sujeiros" e permite a concessão de tutelas jurídicas adequadas à "ética da situação ${ }^{1.3 \%}$, de modo a facilitar a expansão dos bens de personalidade, inclusive mediante implementação dos deveres de proteção que incumbem ao Estado como garante dos Direitos Fundamentais (de personalidade).

Temos que compreender o que o novo Código postula, ao alocat, estrategicamente, seus princípios e cláusulas getais: ao Nómos Basileús ${ }^{14}$, à beteronomia

22 A exposição do pensamento conjectural de Miguel Reale está no seu Verdade e Conjetura. São Paulo, Nova Fronteira, 1983.

${ }^{13}$ A expressão é de REALE, Miguel, en REALE, Miguel. O Código Civil e seus Problemas Fundamentais, São Paulo, Saraiva, 1986.

${ }^{14}$ Lembra Agambem um fragmento de Píndaro, no qual "nómos" revelawse como o poder que opera com "mảo mais forte" a união entre a violência e o direito, definindo a própria soberania pela justificação da violência. A expressão é aqui usada metaforicamente, para designar a leí autoritária que, fundada numa razão nonológica, implicará, necessariamente, violência en relação às situaçōes que não compactuam com a opacidade de uma mesma e sempitena resposta jurídica. (a referência ao fragmento está em AGAMBEN, Giorgio. Homo Sacer. O poder soberano e a vida nua. Tradução de Henrique Burigo. Humanitas, Belo Horizonte, 2002, p. 37). 
autoritária e fechada da codificação oitocentista, substitui o novo Código Civil uma técnica que viabiliza a prospectividade e o raciocínio por princípios, que se dá, necessariamente, no jogo de ponderações com os demais princípios, com as demais tutelas concedidas pelo ordenamento à pessoa Liumana.

Isso significa dizer que o Código Reale atribui, a todos nós, o papel de protagonistas da vida civil e de sua ordenação por meio do Direito. E se temos todos - jurisras ou não - papel ativo no espetáculo da vida na cives, não sendo meros espectadores, temos o dever de perceber que as perspectivas ensejadas pelo novo Código são "responsabilidades hermenêuticas" que só satisfaremos se tivermos consciência de sermos nós os aurores do seu "sentido". Essa responsabilidade, que é a mais alta missão do civilista, resta facilitada ao percebermos que as bases culturalistas do novo Código Civil, elaboradas por Reale, constituem um plástico material para a construção das soluções que harmonizem sua letra com a inregralidade das pautas ordenadoras do ordenamento jurídico relativas à tutela da pessoa humana.

Contudo - é também Reale quem ensinou - para perceber e desempenhar essa responsabilidade é preciso exercitar a nossa liberdade, realizando construção e escolhas porque o tempo da concreção não é o tempo das simplificações, das monologias, das respostas previamente assentadas por um demiurgo personagem.

O exercício da liberdade, a angústia - a agonia - do conhecimento e da descoberta de possíveis respostas; a criatividade do intelecto; e a radical atenção à realidade, Essas são, em suma, as lições que têm sido dadas, há 60 anos, pelo agora mais jovem doutor da Universidade Federal do Rio Grande do Sul. 